\title{
PERANCANGAN SISTEM INFORMASI AKADEMIK PERGURUAN ADVENT CIMINDI BERBASIS WEB DENGAN SMS GATEWAY
}

\author{
Adi Syaputra Simanjuntak \\ PT Link Net Tbk, Jakarta, Indonesia \\ e-mail: adisimanjuntak09@gmail.com
}

\begin{abstract}
Abstrak
Sistem informasi dalam suatu sekolah sangat dibutuhkan dalam penyimpanan data dan mengirim suatu laporan kepada orang tua. Perguruan Advent Cimindi merupakan sekolah dengan standar nasional dan juga memiliki ratusan siswa di dalamnya. Pendataan akademik dengan jumlah sebanyak itu dan keinginan dari orang tua agar dapat menerima informasi tentang anak nya di sekolah mungkin dari sekolah kesulitan untuk menjalankan tugas-tugasnya.

Sistem informasi akademik Perguruan Advent Cimindi berbasis web dengan sms gateway merupakan sistem informasi yang menyediakan pengolahan data akademik siswa Perguruan Advent Cimindi. Penelitian ini dilakukan untuk membuat sebuah sistem pengolahan data siswa dan pengiriman informasi siswa kepada orang tua melalui sms dari sistem. Sistem informasi ini dibuat dengan framework Laravel. Dari penelitian ini dihasilkan fitur yang dapat membantu dalam pengolahan data siswa seperti menginput nilai siswa, menginput absen siswa, menginput laporan pembayaran uang sekolah dan mengirim informasi kepada orang tua. Ke depannya fitur ini diharapkan dapat dikembangkan sehubungan dengan transaksi seperti keuangan siswa.
\end{abstract}

Kata Kunci: Sistem informasi, Framework Laravel, Web, dan Sms Gateway

\section{DESIGN OF WEB-BASED ACADEMIC INFORMATION SYSTEM FOR ADVENT CIMINDI USING SMS GATEWAY}

\begin{abstract}
Information systems in a school are needed in storing data and sending a report to parents. Cimindi advent college is a school with national standards and also has hundreds of students in it. Academic data collection with such a large amount and the desire of parents to be able to receive information about their children at school may be difficult from the school to carry out their duties.

Academic Information System for Advent Cimindi College based on SMS Gateway is an information system that provides academic data processing for Advent Cimindi College students. This research was conducted to create a student data processing system and sending student information to parents via SMS from the system. This information system was created with the Laravel framework. This study produced features that can help in processing student data such as inputting student grades, inputting student absences, inputting tuition payment reports, and sending information to parents. In the future, this feature is expected to be developed in connection with transactions such as student finance.
\end{abstract}

Keywords: Information systems, Laravel Framework, Web, and Sms Gateway 


\section{Pendahuluan}

Dengan berkembangnya ilmu teknologi pada era globalisasi pada saat ini, khususnya dalam bidang komputer sudah berkembang dengan sangat pesat. Dengan adanya peranan komputer yang sangat membantu di dalam menyelesaikan berbagai bidang pekerjaan dan pendidikan. Karena dengan adanya komputer dan internet dapat menghemat waktu dalam menyelesaikan suatu pekerjaan atau menyampaikan suatu informasi dengan cepat dan memberikan hasil yang puas buat penggunanya.

Masalah-masalah sekarang yang sedang dialami oleh orang tua di saat anaknya sudah masuk sekolah yang di mana tentang informasi anaknya di sekolah dalam kehadiran dan dalam keuangannya dan juga dalam nilai pelajaran yang telah di ikutinya di sekolah yang di tempatinya apalagi dalam masalah absensi anaknya di sekolah, kebanyakan anak sekolah sekarang berangkat dari rumah tapi tidak sampai ke sekolah dan orang tua juga tidak tahu informasi absensi anaknya dan orang tua dapat mengetahui tingkat kehadiran anaknya di sekolah hanya pada saat pembagian rapor yang hanya terjadi satu kali setiap semester.

Seiring dengan teknologi yang sangat berkembang pada saat ini sudah banyak teknologi yang bersaing dengan teknologi dan beragam kegunaannya, dan peran informasi juga tidak dapat diabaikan karena semua pasti membutuhkan informasi maupun itu informasi kecil atau besar apalagi di dalam perkembangan teknologi pada saat ini semua kegiatan maupun itu organisasi, sekolah, kantor haruslah menghasilkan informasi yang cepat dan tepat dengan melalui komputer dan maupun itu melalui handphone yang menghasilkan informasi. Oleh karena itu, diperlukan adanya suatu penghubung atau media sebagai jembatan dalam penyampaian informasi keuangan, nilai, dan absen sekolah dalam berbasis web dan SMS Gateway yang digunakan oleh sekolah Advent Cimindi untuk menyampaikan informasi kepada setiap orang tua/wali murid yang akan dikirimkan melalui SMS (Short Message Service) yaitu berupa data absen, keuangan, dan nilai murid [1] [2].

Dengan adanya teknologi atau peranan dari SMS Gateway dan dapat berfungsi sebagai salah satu alat pengirim informasi data dapat membantu pekerjaan guru-guru sekolah Advent Cimindi untuk mengirim informasi kepada orang tua/wali murid dengan cepat dan akurat.

\section{Metode Penelitian}

Pengembangan Aplikasi ini menggunakan metode Waterfallatau dikelan juga sebagai Classic Software Development Life Cycle [3]. Waterfal/merupakan salah satu metode dalam SDLC yang mempunyai ciri khas pengerjaan yaitu setiap fase dalam waterfall harus diselesaikan terlebih dahulu sebelum melanjutkan ke fase selanjutnya. Artinya focus terhadap masing-masing fase dapat dilakukan maksimal karena jarang adanya pengerjaan sifatnya paralel walaupun dapat saja terjadi pararelisme dalam Waterfal. Pengembangan Aplikasi ini dimulai dari tahap: (1) Menganalisa kebutuhan; (2) Mendesain sistem sesuai kebutuhan; (3) Pembangunan sistem; Dan yang terakhir (4) Tahap penyelesaian sistem.

Analisa Sistem baru ini menjelaskan bahwa di dalam sistem yang akan dibangun ini admin/Bendahara meng-input dan mengirim informasi berupa pesan mengenai saldo pembayaran keuangan siswa yang baru saja di setor. dan Admin/Guru akan menginput nilai dan absen siswa dan mengirim pesan mengenai absen atau kehadiran di sekolah dan nilai siswa dan orang tua akan cepat tahu dengan info laporan pembayaran keuangan, absen dan nilai anaknya di sekolah .

Kebutuhan perangkat keras yang digunakan untuk membangun aplikasi ini adalah sebuah Laptop dengan Processor AMD A9-9400 RADEON R5, RAM 4GB,Monitor LCD 14.0", Keyboard \& Mouse. Sedangkan beberapa perangkat lunak yang digunakan dalam pengembangan aplikasi berbasis Website menggunakan framework Laravel ini adalah Balsamiq mockup,Xampp,Sublime Text 3, Visual Studio Code

\section{Use Case Diagram}

Use Case merupakan kumpulan skenario yang menggambarkan interaksi antara sistem dan user. Use Case Diagram menampilkan hubungan antara sejumlah aktor dengan berbagai Use Case [4]. aktor mewakili user atau sistem lain yang berinteraksi dengan sistem yang dimodelkan. Use Case adalah sebuah external 
dari sistem yang mewakili berbagai action yang mungkin user lakukan untuk tujuan menyelesaikan sebuah task, berikut adalah fungsi yang dijelaskan dalam bentuk use case diagram.

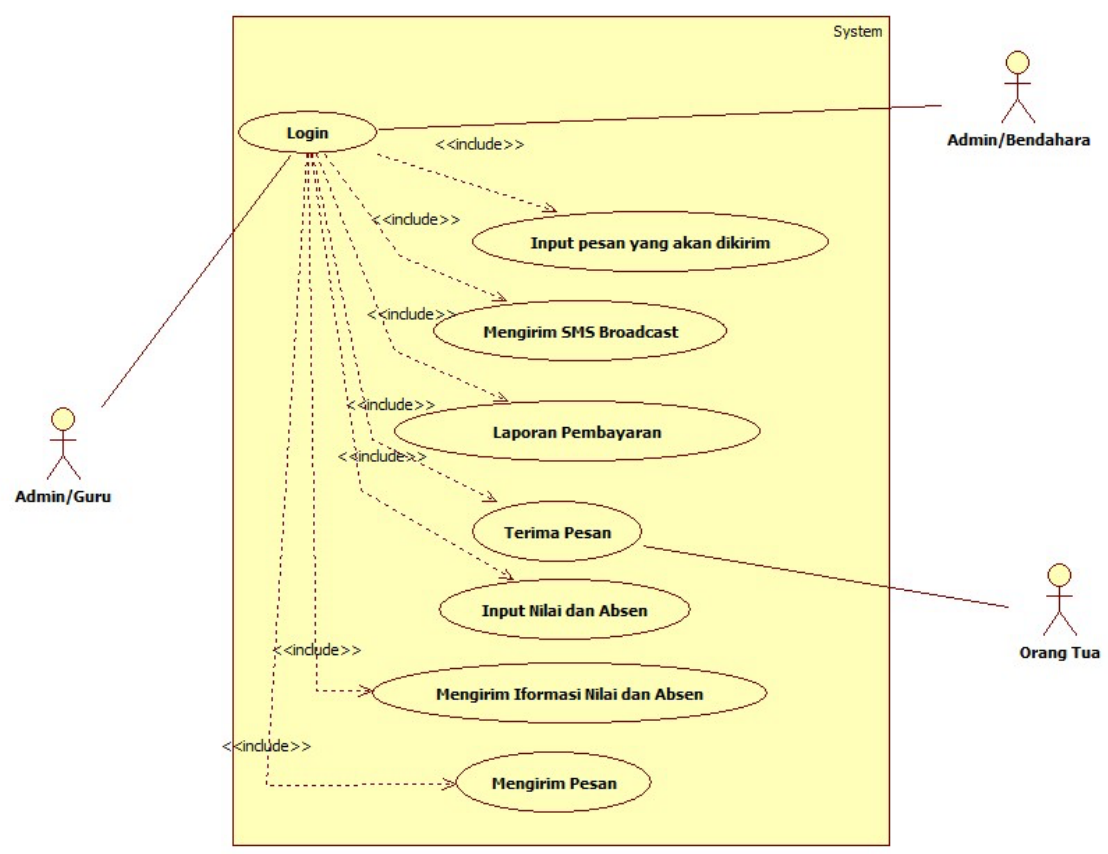

Gambar 1 Use Case Diagram

Use Case dari sistem ini adalah Bendahara dan Guru terlebih dahulu login, memasukkan username dan password agar dapat masuk ke sistem ,Setelah itu admin/guru dan admin/bendahara akan masuk ke halaman utama. Admin/guru dan admin/bendahara dapat mengirim pesan yang akan dikirim ke orang tua. Lalu Orang tua dapat menerima pesan.

\section{Activity Diagram}

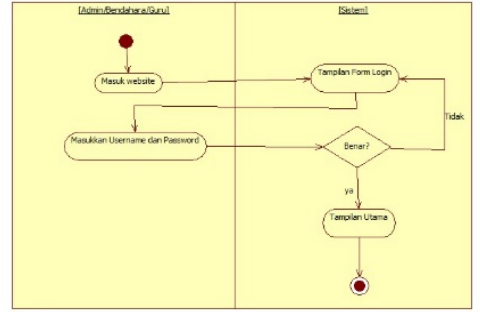

Gambar 2 Activity Diagram Login

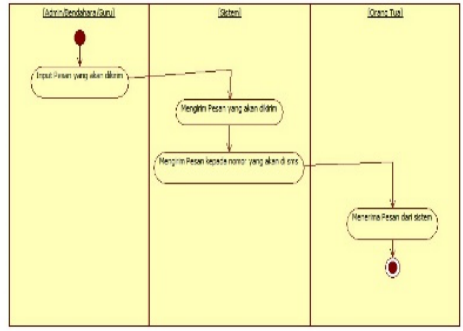

Gambar 3 Activity Diagram Input Pesan Yang Akan Dikirim

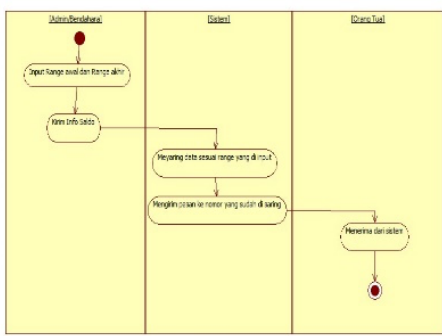

Gambar 4 Activity Diagram Bendahara Mengirim SMS Broadcast

Pada Gambar 2 menjelaskan Activity Diagram dalam proses masuk ke dalam menu utama, disaat Admin/Bendahara/Guru akan terlebih dahulu melewati form login apabila username dan password yang dimasukkan salah maka akan kembali ke tampilan login dan jika berhasil maka akan masuk ke tampilan utama. Pada Gambar 3.3 menjelaskan activity diagram tentang proses aktivitas di saat Admin/Guru dan Admin/Bendahara ingin menginput pesan yang akan dikirim, adapun penyelesaiannya sebagai berikut: 1 . Admin/Guru dan Admin/Bendahara, menginput pesan yang akan dikirim, 2.Sistem akan mengirimkan data berbasis $S M S$ ke nomor telepon yang sudah dimasukkan,3.Orang Tua akan menerima SMS dari sistem. Pada gambar ini menjelaskan Activity Diagram tentang proses aktivitas ketika admin/Bendahara ingin 
mengirim sms broadcast, adapun penjelasan gambar di atas sebagai berikut: 1.Admin/Bendahara menginput jumlah range yang akan dikirim, 2.Admin/Bendahara akan melakukan pengiriman info pembayaran,3. Sistem akan menyaring data sesuai range yang sudah di input, 4 . Sistem akan mengirimkan pesan kepada nomor yang telah disaring,5. Orang tua akan menerima pesan dari sistem

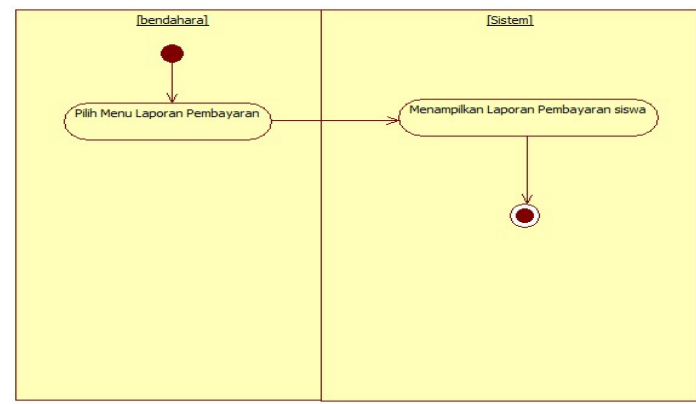

Gambar 5.Activity Diagram Bendahara Mengirim Laporan Pembayaran

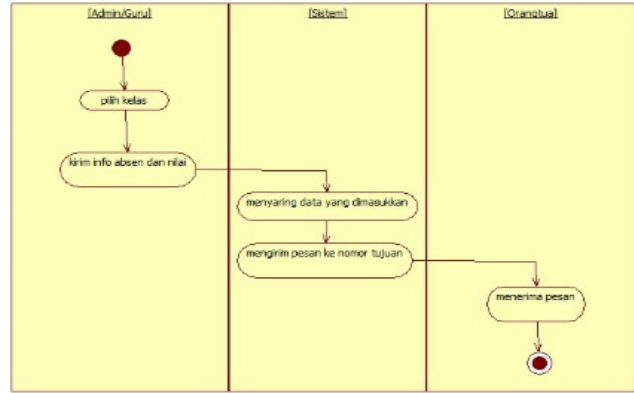

Gambar 6. Activity Diagram Guru Mengirim SMS Broadcast

Pada Gambar 5 menjelaskan activity diagram tentang proses Admin/Bendahara tampilan laporan pembayaran uang sekolah siswa, adapun penjelasan di atas sebagai berikut: Admin/Bendahara akan memilih menu laporan pembayaran dan akan melihat laporan pembayaran yang suda ditambahkan dari tambah pembayaran.

Pada Gambar 6 menjelaskan Activity Diagram tentang aktivasi di saat Admin/Guru mengirimkan SMS broadcast, adapun penjelasan gambar di atas adalah sebagai berikut: 1.Admin/Guru memilih kelas siswa yang akan dikirim nilai dan absennya, 2.Admin/Guru akan mengirim info nilai dan absen siswa,3. Sistem akan menyaring data dengan sesuai nilai rendah dan absen yang sudah di tentukan guru,4.Sistem akan mengirim ke nomor telepon yang telah disaring,5. Orang tua menerima pesan dari sistem.

\section{Sequence Diagram}

Sequence diagram adalah suatu diagram yang menggambarkan interaksi antara objek dan mengindikasikan komunikasi diantara objek-objek tersebut, Diagram ini juga menunjukkan serangkaian pesan yang dipertukarkan oleh objek-objek yang melakukan suatu tugas atau aksi tertentu.

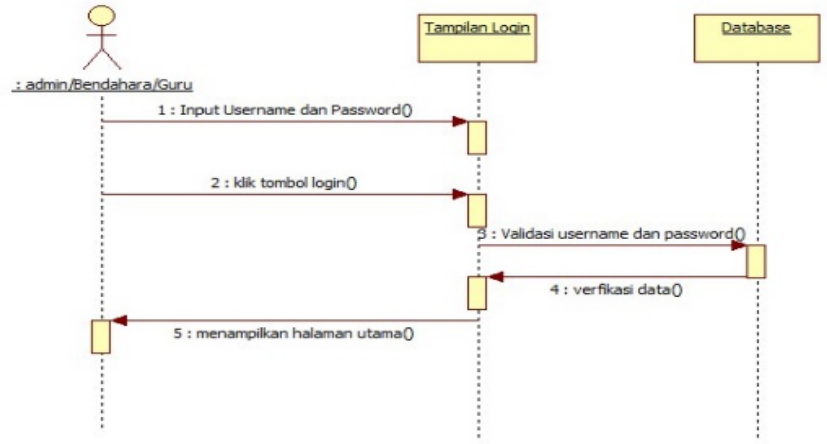

Gambar 7 Sequence Diagram Login

Pada Gambar 7 sequence diagram login adalah proses Admin/Bendahara/Guru memasukkan Username dan Password ke sistem lalu divalidasi. Jika proses validasi selesai maka sistem akan menampilkan halaman utama website. 


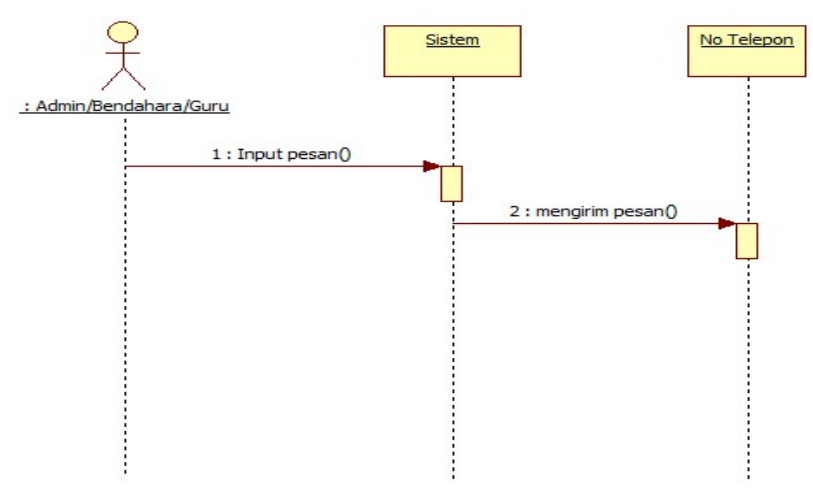

Gambar 8 Sequence Diagram Input Pesan Yang Akan Dikirim

Pada Gambar 8 Sequence Diagram Input pesan yang akan dikirim, Admin akan memasukkan pesan yang akan dikirim dan mengirim pesan ke nomor yang telah dimasukkan ke sistem dan setelah dikirim ke nomor tujuan maka nomor tujuan akan menerima pesan dari sistem.

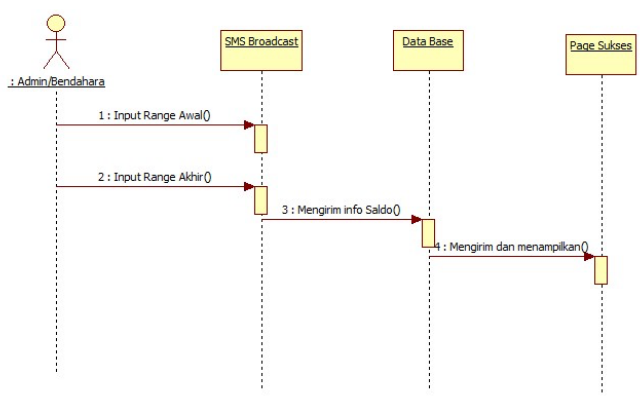

\section{Gambar 9 Sequence Diagram Bendahara Mengirim SMS Broadcast}

Pada Gambar 9 Sequence Diagram Bendahara Mengirim SMS Broadcast dimana Admin mengirim sms broadcast tentang laporan pembayaran siswa, dengan memasukkan range awal dan memasukkan range akhir maka akan keluar nama-nama siswa dengan range yang sudah dimasukkan dan admin menekan tombol mengirim info saldo dan setelah mengirim info laporan pembayaran maka admin akan melihat tampilan pengiriman sukses.

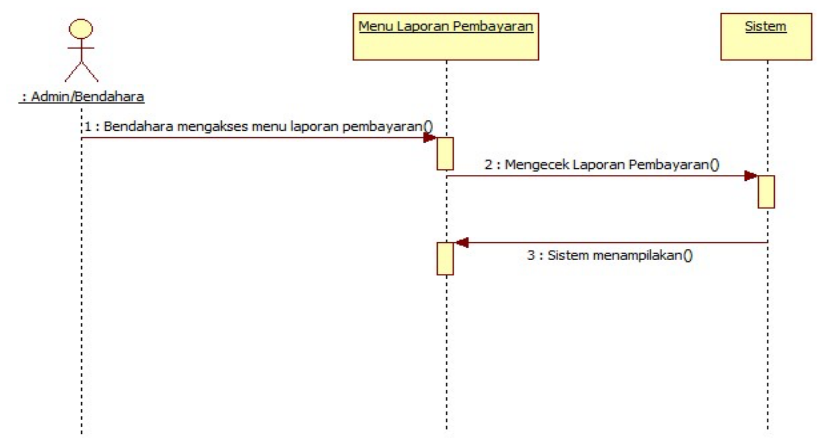

Gambar 10 Sequence Diagram Laporan Pembayaran

Pada Gambar 10 Sequence Diagram Laporan Pembayaran di mana proses gambar di atas, admin dapat melihat laporan pembayaran uang sekolah yang dimana hasil dari input tambah pembayaran dan maka bendahara akan melihat hasil tampilan pembayaran yang sudah dibayar oleh siswa. 


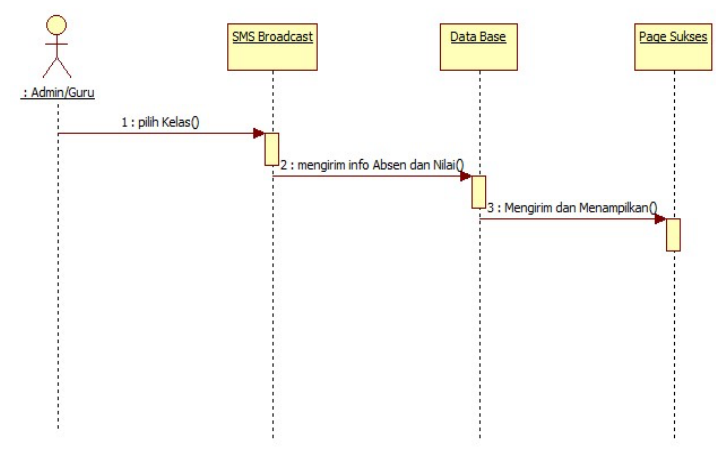

Gambar 11 Sequence Diagram Guru SMS Broadcast

Pada Gambar 11 Sequence Diagram Guru SMS Broadcast adalah proses Admin/Guru mengirim sms broadcast dengan memilih kelas dan mengirim info absen dan nilai siswa dan sistem akan menampilkan pengiriman sukses.

\section{Class Diagram}

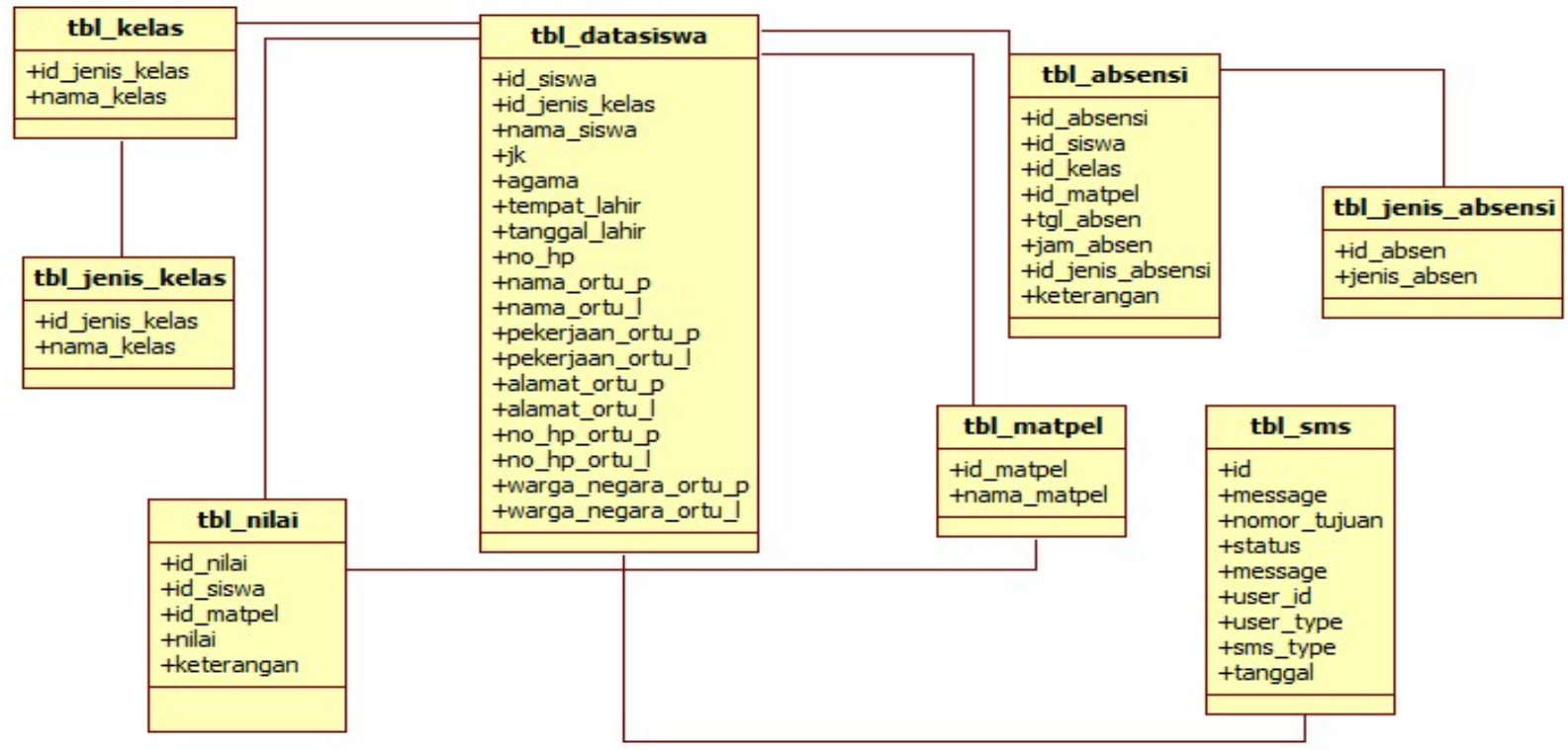

Gambar 12 Class Diagram

\section{Perancangan Antarmuka}

Perancangan antarmuka adalah di mana tampilan-tampilan yang ada pada aplikasi yang akan dibuat dari login hingga fitur-fitur yang ada di dalam aplikasi dan akan ditampilkan dalam bentuk Mockup, agar mempermudah pembaca untuk mengerti bagaimana isi tampilan. 


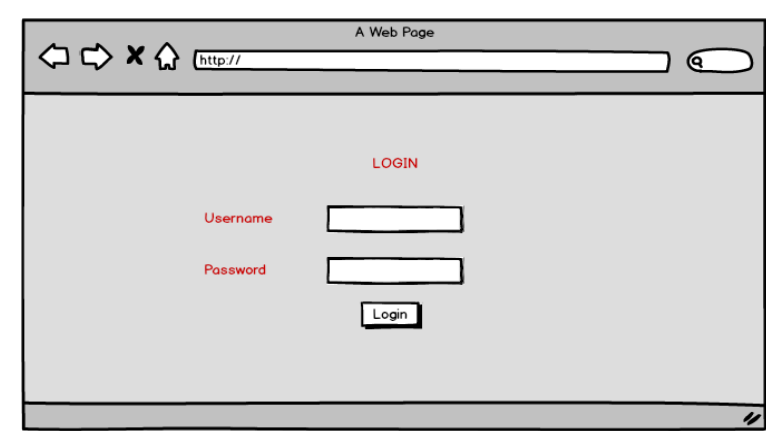

Gambar 13 Halaman Login

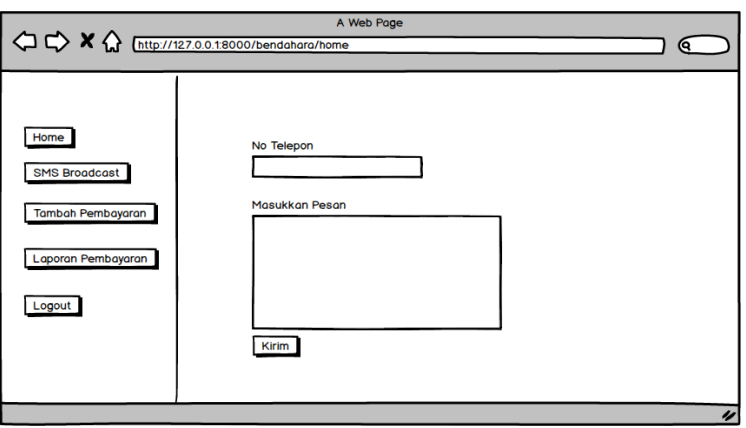

Gambar 14 Tampilan Halaman Utama Bendahara

Pada Gambar 13 merupakan tampilan perancangan antar muka untuk tampilan login admin/Bendahara/Guru. Pada Gambar 14 merupakan tampilan halaman pertama atau halaman utama bendahara setelah login pada halaman ini menunjukkan Admin/Bendahara dapat mengirim pesan dengan memasukkan nomor dan menulis pesan yang akan di kirimkan ke nomor HP yang di ingin dikirim.

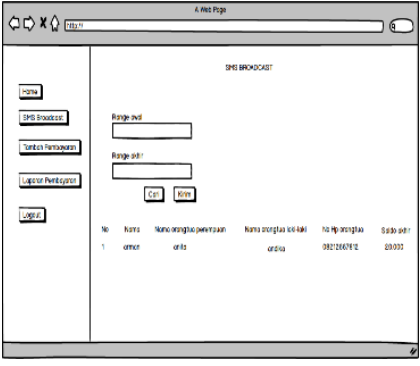

Gambar15 Tampilan Halaman SMS Broadcast Bendahara

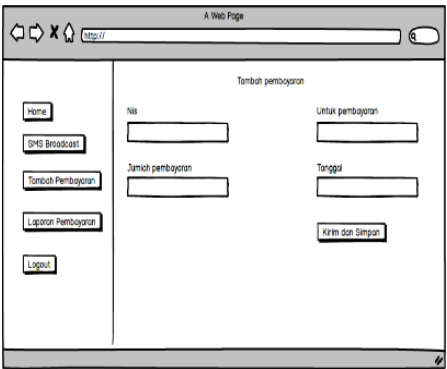

Gambar 16 Tampilan

Tambah Pembayaran

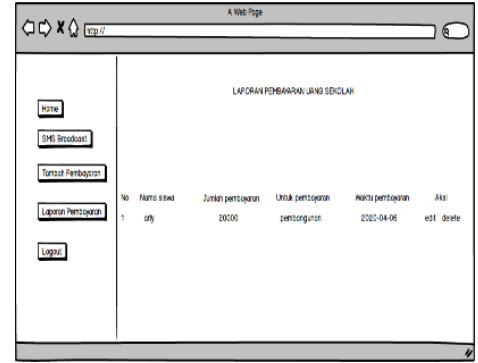

Gambar 17 Tampilan

Menu Pembayaran

Pada Gambar 15 merupakan tampilan dimana ada beberapa menu seperti: range awal dan range akhir yang dapat melakukan filter ,kirim info saldo yang dapat mengirim pesan kepada nomor handphone orang tua yang sudah tersimpan di database. Pada gambar 16 merupakan tampilan tambah pembayaran uang sekolah yang dimana ada pada gambar di atas bahwa admin/bendahara menginput nama siswa, menginput jumlah pembayaran, menginput uang pembayaran seperti uang senior atau pun uang sekolah, menginput tanggal pembayaran, lalu admin akan menekan tombol kirim dan simpan maka pesan akan terkirim kepada orang tua dan pesan juga akan tersimpan setelah sudah dikirim di laporan pembayaran. Pada Gambar 17 merupakan tampilan laporan pembayaran, hanya tampilan daftar pembayaran apabila siswa telah membayar uang sekolah maka akan masuk ke tampilan laporan pembayaran uang sekolah.

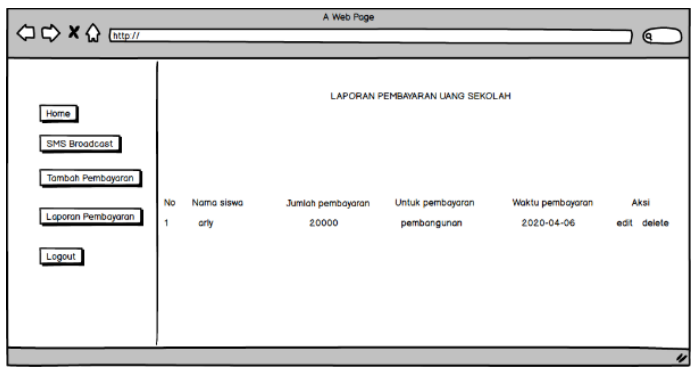

Gambar 18 Tampilan Halaman Laporan Pembayaran Uang Sekolah 
Pada Gambar 18 merupakan tampilan laporan pembayaran, hanya tampilan daftar pembayaran apabila siswa telah membayar uang sekolah maka akan masuk ke tampilan laporan pembayaran uang sekolah.

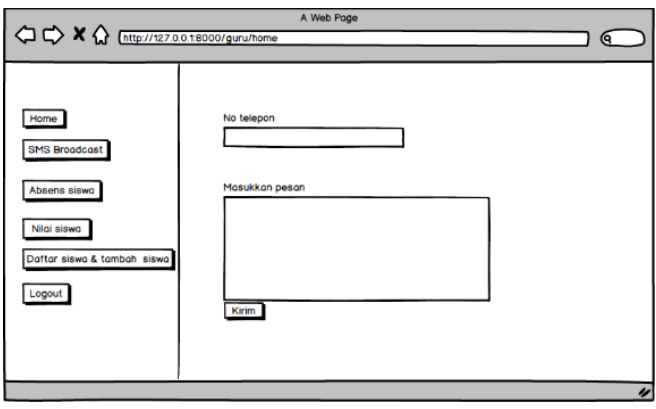

Gambar 19 Tampilan Halaman Utama Guru

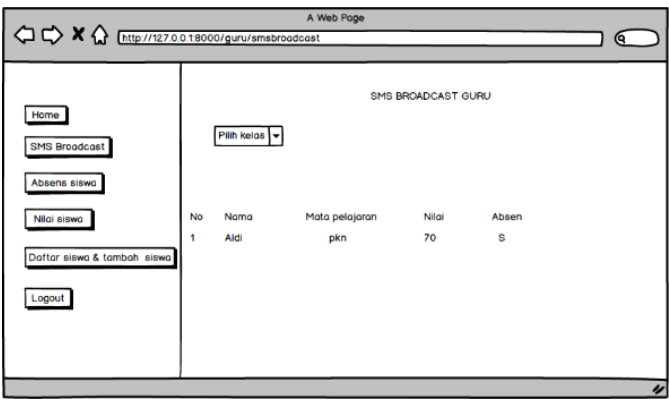

Gambar 20 Tampilan Halaman Broadcast Guru

Pada Gambar 19 merupakan tampilan halaman pertama atau halaman utama Guru setelah login pada halaman ini menunjukkan Admin/Guru dapat mengirim pesan dengan memasukkan nomor dan menulis pesan yang akan di kirimkan ke nomor hp yang di ingin dikirim. Pada Gambar 20 merupakan tampilan sms broadcast, admin/Guru dapat mengirim nilai dan absen ke nomor orang tua yang sudah tersimpan di database.

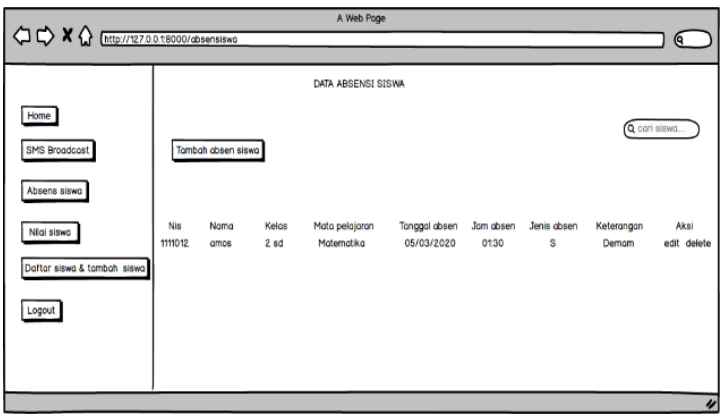

Gambar 21 Tampilan Halaman Data Absen Siswa

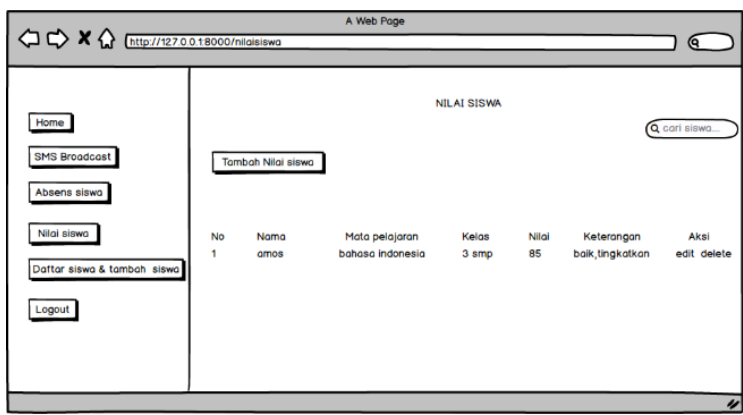

Gambar 22 Tampilan Halaman Data Nilai

Pada Gambar 21 merupakan tampilan data absen siswa yang dimana Admin/Guru akan mencari kelas atau NIS siswa di pencarian di sebelah kiri tampilan, dan guru dapat menginput data absensi siswa dengan menekan tombol tambah absen siswa. Pada Gambar 22 merupakan tampilan halaman untuk memasukkan nilai, dimana Admin/Guru akan menekan tombol tambah nilai siswa, untuk menginput nilai siswa.

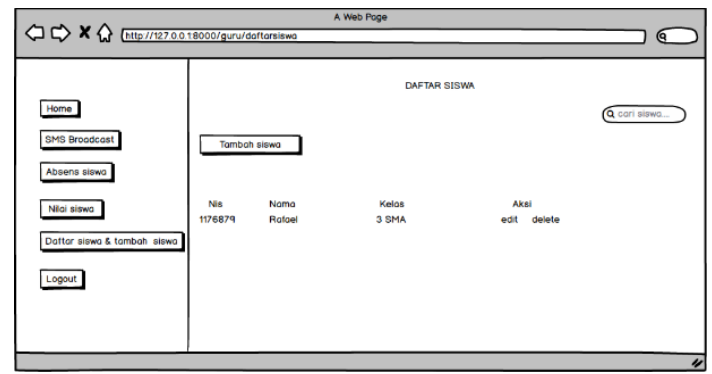

Gambar 23 Tampilan Halaman Daftar Siswa Dan Tambah Siswa 
Pada Gambar 23 merupakan tampilan untuk memasukkan siswa atau tambah siswa yang dimana admin/Guru dapat menekan tombol tambah siswa untuk menambah siswa dan dapat mencari siswa dengan kolom pencarian yang ada di sebelah kanan tampilan dengan memasukkan nis siswa.

\section{Hasil}

Program yang dibuat adalah aplikasi sistem akademik dalam input absensi siswa, input nilai siswa dan juga dan juga laporan info laporan pembayaran uang sekolah melalui sms gateway. Berikut adalah tampilan dari aplikasi yang sudah dirancang,

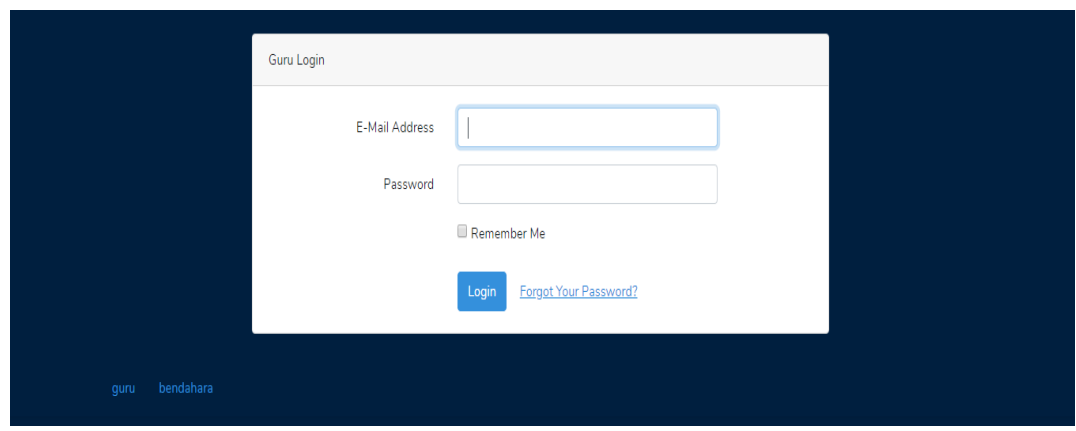

Gambar 24 Halaman Login

Pada gambar 24 Tampilan login adalah halaman depan sebelum masuk ke halaman utama. Dalam tampilan ini terdapat username dan password yang harus diisi sebelum masuk dalam ke dalam menu utama sistem akademik
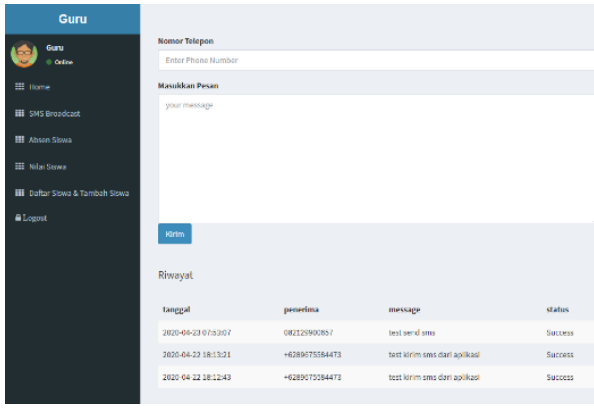

Gambar 25 Tampilan Halaman sms Guru
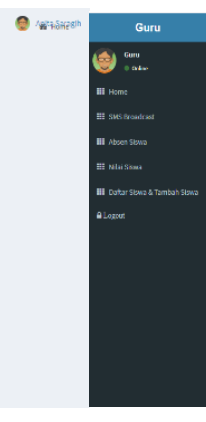

Gambar 26 Tampilan SMS Broadcast Guru

Pada gambar 25 ini adalah halaman utama Guru setelah login dimana Admin/Guru dapat memasukkan no telepon dan pesan dan akan mengirim pesan yang telah dimasukkan. Pada gambar 26 ini admin/Guru dapat mengirimkan nilai dan absen siswa kepada nomor yang telah diarahkan dan memilih siswa kelas berapa yang akan ingin dikirim. 

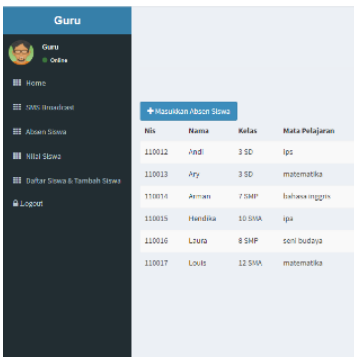

DATA ABSENSI SISWA

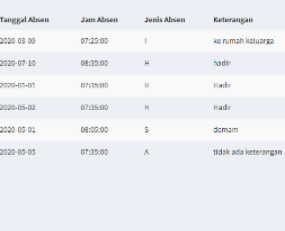

Gambar 27 Tampilan Absensi Siswa

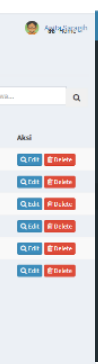

Gambar 28Tampilan Daftar Nilai Siswa Dan

Pada gambar 27 ini ,Admin/Guru dapat meng input absen siswa melalui tombol tambah siswa. Pada gambar 28 ini menunjukkan Admin/Guru dapat menginput nilai siswa dan melihat daftar absensi siswa setelah menekan tombol tambah nilai siswa.

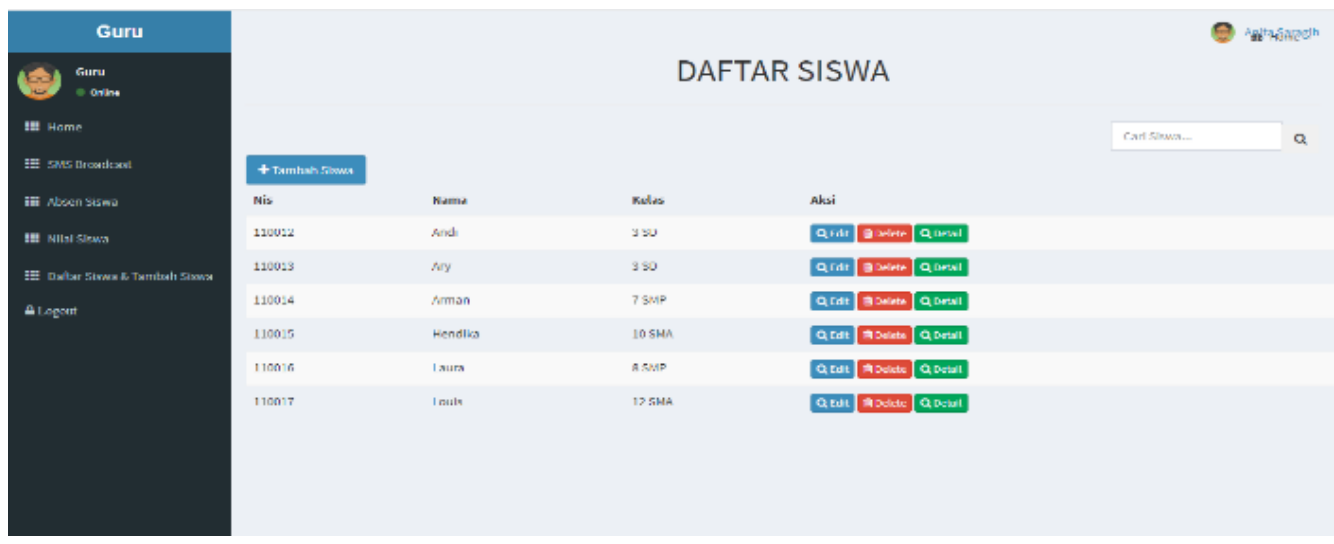

Gambar 29 Tampilan Daftar Siswa Dan Menambah Siswa

Pada gambar 29 menjelaskan bahwa Admin/Guru dapat menambah siswa dengan menekan tombol tambah siswa dan nanti akan mengisi data-data siswa dan guru juga dapat mencari siswa dengan pilih kelas dan dalam kolom pencarian di sebelah kanan dengan memasukkan NIS siswa yang ingin di cari.

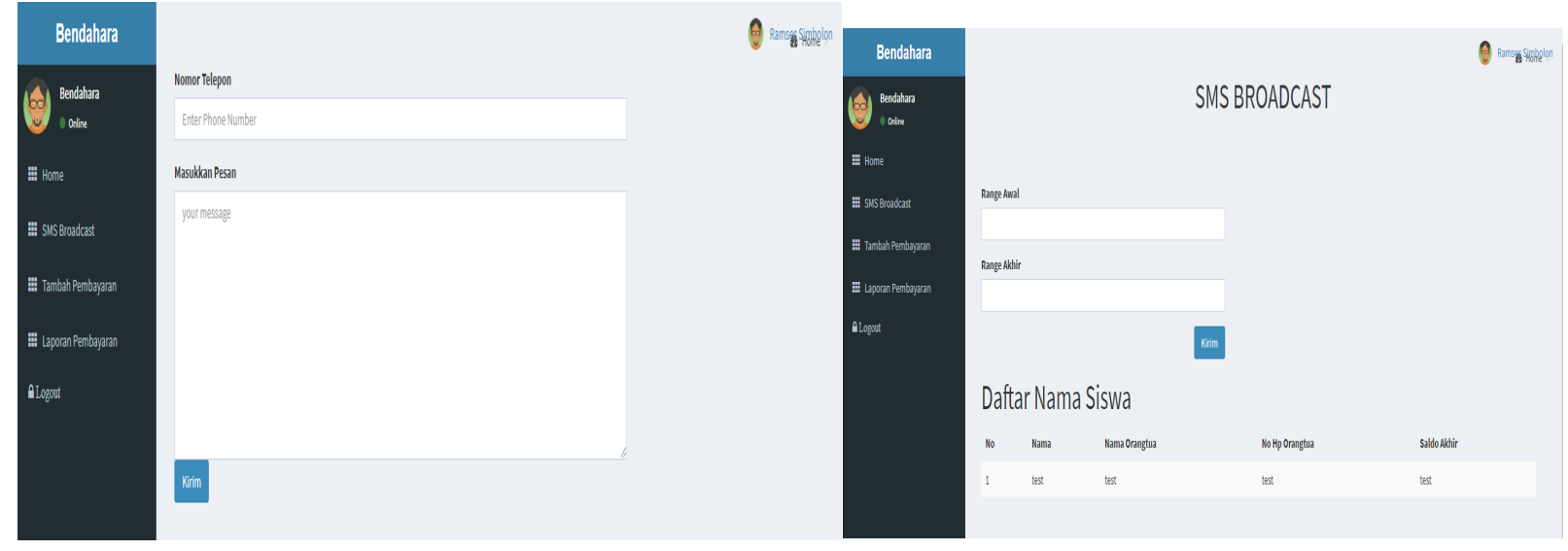

Gambar 30 Tampilan Halaman Utama Bendahara

Gambar 31 Tampilan SMS Broadcast Bendahara 
Pada gambar 30 ini adalah halaman utama Admin/Bendahara setelah login yang dimana di tampilan ini Admin/Bendahara dapat menginput nomor tujuan dan menginput pesan yang akan dikirim kepada nomor tujuan. Gambar 31 menu ini menunjukkan Admin/Bendahara akan memasukkan nilai jumlah uang ke dalam range awal dan range akhir dimana akan muncul jumlah hutang yang telah dimasukkan oleh bendahara dan akan mengirim pesan ke orang tua siswa dengan melalui SMS Broadcast.

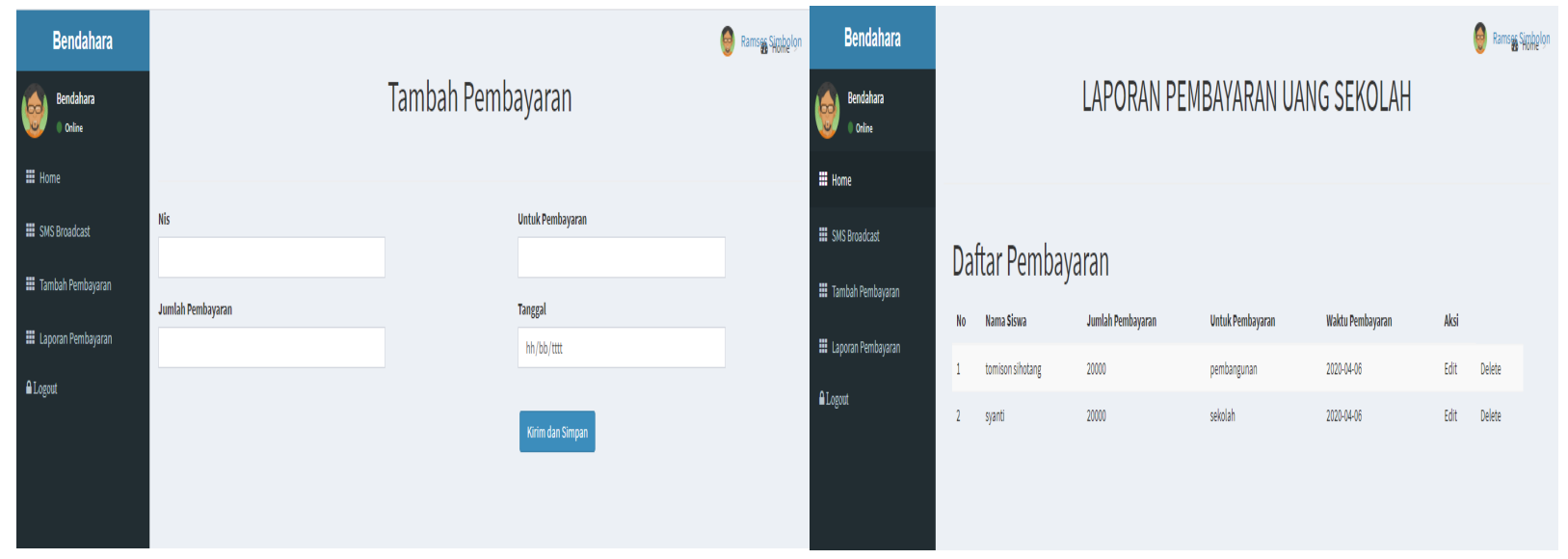

Gambar 32 Tampilan Pembayaran Uang Sekolah Gambar 33 Tampilan Laporan Pembayaran

Gambar 32 menu ini menunjukkan bahwa Admin/Bendahara menginput keuangan siswa dengan memasukkan Nis, jumlah pembayaran, untuk pembayaran, dan juga tanggal pembayaran dan setelah itu bendahara akan menekan tombol kirim dan simpan, dimana pesan akan terkirim kepada no tujuan dan akan tersimpan di laporan pembayaran. Gambar 33 menu ini adalah laporan pembayaran uang sekolah dimana Admin/Bendahara akan dapat melihat laporan pembayaran uang sekolah.

\section{BlackBox Testing}

Blackbox testing adalah Suatu percobaan dalam aplikasi yang telah dirancang apakah dapat berjalan dengan sesuai yang telah dirancang dari awal [5].

Dengan hasil di bawah ini dalam memastikan fungsi-fungsi dari sistem, peneliti telah rancang telah berjalan sesuai dengan yang telah diharapkan dimana dengan menggunakan metode blackbox.

Tabel 1. Pengujian blackbox testing aplikasi

\begin{tabular}{|c|l|l|l|c|}
\hline No & \multicolumn{1}{|c|}{ Input/event } & \multicolumn{1}{|c|}{ Proses } & \multicolumn{1}{|c|}{ Output } & Keterangan \\
\hline 1. & \multicolumn{1}{|c|}{ Login } & $\begin{array}{l}\text { Memasukkan } \\
\text { username dan } \\
\text { password }\end{array}$ & Tampilan Home & sesuai \\
\hline 2. & $\begin{array}{l}\text { Input Pesan Yang } \\
\text { Akan Dikirim }\end{array}$ & $\begin{array}{l}\text { Menampilkan kolom } \\
\text { input nomor } \\
\text { handphone dan input } \\
\text { pesan }\end{array}$ & $\begin{array}{l}\text { Tampil Layout } \\
\text { SMS sudah } \\
\text { terkirim }\end{array}$ & Sesuai \\
\hline 3. & $\begin{array}{l}\text { Mengirim SMS } \\
\text { Broadcast }\end{array}$ & $\begin{array}{l}\text { Menampilkan daftar } \\
\text { siswa yang sudah } \\
\text { dicari }\end{array}$ & $\begin{array}{l}\text { Tampil Layout } \\
\text { broadcast berhasil } \\
\text { dikirim }\end{array}$ & Sesuai \\
\hline 4. & $\begin{array}{l}\text { Laporan } \\
\text { Pembayaran }\end{array}$ & $\begin{array}{l}\text { Menampilkan laporan } \\
\text { pembayaran }\end{array}$ & $\begin{array}{l}\text { Menampilkan } \\
\text { Data laporan } \\
\text { pembayaran }\end{array}$ & Sesuai \\
\hline
\end{tabular}




\begin{tabular}{|c|l|l|l|c|}
\hline 5. & $\begin{array}{l}\text { Input Nilai Dan } \\
\text { Absen }\end{array}$ & $\begin{array}{l}\text { Menampilkan kolom } \\
\text { input Nilai dan Absen }\end{array}$ & $\begin{array}{l}\text { Tampil Layout } \\
\text { absen dan nilai } \\
\text { berhasil di input }\end{array}$ & Sesuai \\
\hline 6. & $\begin{array}{l}\text { Input Pembayaran } \\
\text { Uang Sekolah }\end{array}$ & $\begin{array}{l}\text { Memasukkan } \\
\text { nis,jumlah } \\
\text { pemayaran,untuk } \\
\text { pembayaran,dan } \\
\text { tanggal }\end{array}$ & Data Tersimpan & Sesuai \\
\hline 7 & Terima Pesan & $\begin{array}{l}\text { Pesan Dikirim Ke } \\
\text { Nomor Tujuan }\end{array}$ & $\begin{array}{l}\text { Pesan Diterima } \\
\text { Oleh Nomor } \\
\text { Tujuan }\end{array}$ & sesuai \\
\hline 8 & $\begin{array}{l}\text { Tampilan } \\
\text { Informasi Nilai } \\
\text { Dan Absen }\end{array}$ & $\begin{array}{l}\text { Menampilkan Data } \\
\text { Absen Dan Nilai }\end{array}$ & $\begin{array}{l}\text { Menampilkan } \\
\text { Jumlah Absen } \\
\text { Dan Nilai }\end{array}$ & sesuai \\
\hline
\end{tabular}

\section{Kesimpulan dan Saran}

Setelah menyelesaikan perancangan sistem akademik Perguruan Advent Cimindi penulis dapat mengambil beberapa kesimpulan sebagai berikut:

1. Sistem informasi akademik dapat digunakan untuk membantu dalam penyimpanan data siswa dalam laporan pembayaran, absensi, dan nilai siswa dan dapat dipahami oleh pengguna.

2. Sistem informasi akademik dapat digunakan dalam membantu mengirim informasi melalui sms kepada orang tua melalui sistem. tentang laporan pembayaran, absen, dan nilai siswa

3. Sistem informasi akademik dapat digunakan dengan mudah

Setelah menyelesaikan perancangan sistem akademik Perguruan Advent Cimindi penulis dapat mengambil beberapa kesimpulan sebagai berikut:

1. Penulis menyarankan mengembangkan sistem pembayaran keuangan sekolah dan sistem keamanan.

2. Perlunya pengembangan data informasi siswa dalam keuangan maupun absensi dapat import ke Microsoft Excel agar masuk ke dalam database.

\section{Daftar Pustaka}

[1] I. P. A. E. Pratama, Sistem Informasi dan Implementasinya, Bandung: Informatika Bandung, 2014.

[2] M. H. Masruri, Membangun SMS Gateway dengan Gammu dan Kalkum, Jakarta: PT Elex Media Komputindo, 2015.

[3] M. F. Yurindra S.Kom., SOFTWARE ENGINEERING, Yogtakarta: CV BUDI UTAMA, 2017.

[4] M. Muslihudin and Oktafianto, Analisis Dan Perancangan Sistem Informasi, Yogyakarta: CV ANDI OFFSET, 2016.

[5] P. ASTUTI, "PENGGUNAAN METODE BLACK BOX TESTING (BOUNDARY VALUE ANALYSIS)," pp. 186-195, 2018. 